DE

DE GRUYTER

OPEN

10.1515/topling-2017-0012

\title{
"And this is the view from outside my window": On text and image interplay in university website blogs
}

\author{
Renáta Tomášková \\ University of Ostrava, Czech Republic
}

\begin{abstract}
The paper focuses on the institutional website as a complex genre with a relatively discontinuous inner structure, which is, however, coherent and cohesive, and unified by a common communication goal(s). The website is viewed as a discourse colony consisting of independent but related components realized in an array of subgenres, some of which are typical of the academic/institutional environment while others come from different discourse domains and are employed as embedded genres. The paper focuses on the blog as an embedded genre, its forms and functions within university websites, and particularly on its potentially multimodal character, i.e. the interplay of the verbal content of the blog and the non-verbal elements, esp. photographs, which co-create the producer's message to the addressee. Drawing upon the recently developed field of multimodal discourse analysis within Hallidayan Systemic Functional Linguistics, particularly Martinec and Salway's model, the paper explores the level to which the modes are integrated and the ways they contribute to meaningmaking in the genre.
\end{abstract}

\section{Key words}

institutional discourse, university website, discourse colony, genre set, blog, genre embedding, multimodality, text-image interplay

\section{Introduction}

The institutional website represents a relatively new web genre, which, however, has in recent years developed into a wellestablished generic form shaped by globally spread conventions but allowing for local culture-specific features. With the growing affordances of digital technologies the genre of website has evolved into a multimodal ensemble pursuing its communicative goal through a complex interplay of a variety of modes: employing texts, images, audio and audio-visual recordings, layout and colours. The website can also be viewed as a hybrid genre realized as a genre set, as defined by Bazerman (2004), i.e. as a series of genres that contribute to achieving or co-operate to achieve a common objective. Next to regular genres traditionally related to university presentation materials such as prospectuses, department descriptions, articles on university history, instructions for admission and syllabi, university websites incorporate genres that originated outside the institutional discourse domain and primarily occur elsewhere on the web. Such embedded genres may include e.g. frequently asked questions (FAQs) or blogs. The discontinuous structure of the website complies with Hoey's concept of discourse colony $(1986 ; 2001)$ : it consists of a variety of relatively independent components which are, however, firmly framed by their 
affiliation to the university presentation material signalled by layout, colour patterns or lexical cohesion, and are unified by a common communication goal of presenting the university and promoting it.

The genre of the blog itself appears within university websites in an array of varieties, representing either the institution as a whole and then accessible from the home page, or relating to its constituents faculties, departments, centres, research teams, academics and students - and thus located deeper in the hierarchy of the hypertext. Variability can also be observed in the types of blog as classified according to authorship or topic areas covered (classification based on Herring et al., 2005): university websites offer both community and individual blogs, provide links to blogs presenting personal attitudes and experiences as well as to blogs discussing specific topics, and even more importantly, many of the blogs surveyed exhibit hybrid features blending the personal and the topical, or alternating individual and community posts.

The present paper focuses on student blogs. Student blogs are written by current students but run - as all university website blogs - by the university administration that inspires their realisation and invites students to contribute, at the same time emphasizing that the content of the posts is not controlled by the administrators but left to the decision of the student authors. Student blogs target prospective students and are thus accessed from the prospective students home page. Student blogs are typical examples of hybrid blog forms, speaking for the student community as well as for the individuality of the blogger, merging personal confessions with professional topics (for more detail see Tomášková, 2016).

The technological affordances supporting the format of the genre not only offer space for interaction, introducing a comments section, they also facilitate the multimodal realization of the posts allowing for the employment of photographs, gifs, graphs and diagrams, and provide for the hypertext nature of the web genre enabling insertions of links to websites and web pages outside the blog page, or outside the university website as such.

Whereas the comments sections are rarely used, non-verbal modes as well as links tend to be involved relatively frequently, collaborating with texts to build communication strategies and achieve communication goals. The present study focuses on the employment of photographs, aiming to explore the role(s) they play within blog posts and the ways they interact with texts.

\section{Methodological framework and the corpus}

The analysis of the multimodal realization of student blog posts is grounded in the social semiotic approach to language and communication as developed by Halliday in his systemic-functional linguistics (1978; 2004) and built upon by his followers, including multimodal discourse analysts (cf. Lemke, 2012; O'Halloran, 2004). As Lemke explains (2012, p.81), Halliday provided a particularly inspirational framework for the study of verbal and nonverbal communication because his linguistic theory was embedded within the broader concept of social semiotics:

it was a model of the relationship of language to society and it held that meaning was made by language in use in a context of situation and in a context of culture. Every different social setting evoked a different meaning potential, a different set of probabilities that particular meanings would be made by using particular resources from the grammar of language.

As all communication is multimodal, realized through an interplay of several modes, and "all communicative behaviour takes place in social contexts and for social purposes" (Bateman, 2014, p.45, emphasis in the original), Halliday's model is easily applicable not only to describe other semiotic modes on their own but could also help explain their mutual relations.

Thus Halliday's theory is seen and applied as:

concerned with the underlying design (or 'grammar') of semiotic resources and their relations with each other, specified as inter-related semantic systems which are seen to fulfil four functions: to construe our experience of the world (experiential meaning); to create logical relations between 
experiential meanings (logical meaning), to enact social relations (interpersonal meaning) and to organise meanings into coherent messages in text (textual meaning) (O'Halloran, 2012, n.p.).

This does not imply that the designs of semiotic resources correlate in a mechanical way, or that the models of their analysis could count with parallel designs down to the lower levels of analysis. While the specificities of individual modes need to be recognized (Bateman, 2014, p.46), a way towards revealing the principles of their collaboration may be found on the higher levels of analysis, namely on the level of discourse semantics (Bateman and Wildfeuer, 2014, p.181).

Mode, defined in line with Kress, "is a socially shaped and culturally given resource for making meaning" (Kress, 2009, p.54). Kress's approach does not lean only on the general distinction between visual, aural and audio-visual resources, but prefers to focus on the characteristic features and mutual relations of their specific representatives: image, writing, layout, music, gesture, speech and moving image, which are seen as individual modes. In accordance with the social semiotic theory of the Hallidayan school, the constitutive feature of a mode is seen in its capacity to represent the reality of the world, the social relations of participants in communication, and to represent both as a coherent message - in other words to fulfil the ideational, interpersonal and textual metafunctions (Kress, 2009, p.59; 2010; cf. Tomášková, 2015).

Kress's concept of mode is also recognized by Bateman (2011), who, however, builds on his definition further to achieve a more fine-grained distinction between the modes. Bateman sees modes as complex entities exhibiting a threestratal structure. A semiotic mode thus includes "a non-material component taking in both the content and expression planes and, in addition to these, a material component" (Bateman, 2011, p.21; highlighting in the original) and this semiotic code could only be interpreted in context, as part of discourse, in other words it needs to be placed within the third stratum of discourse semantics (Bateman, 2011, p.22). Written language is thus a distinct semiotic mode distinguished from spoken language by its materiality, and at the same time one material component e.g. a visual substrate - may carry a set of individual modes such as writing, image and layout (Bateman, 2011 , p.24) which are then co-present in visual media. A web page typically manifests the presence of all three visual modes mentioned in the previous sentence, so the meanings it produces could be analysed through textflow, image-flow and page-flow, i.e. the layout and their interaction (Bateman, 2011, p.26). The present study concentrates on the interplay of two of these, namely text and image.

One of the models for analysis developing the potential of Halliday's approach for investigation of images is Kress's and van Leeuwen's visual grammar (2006 [1996]), which provides a sophisticated tool for analysing the structure of images (cf. Tomášková, 2015) but does not concentrate on the details of text-image interaction.

As in the present paper the structure of the images themselves is only of marginal concern, the essential mainstay of the analysis was found in the system of imagetext relations elaborated by Martinec and Salway (2005). Respected for a genuine effort at precision (cf. Bateman, 2014), Martinec and Salway's pattern draws upon the early treatise on text-image relations by Barthes (1997a [1961]; 1997b [1964]) and adopts the system of logico-semantic relations as introduced by Halliday (1985).

Barthes distinguished three typologically distinct relations texts and images may enter into, namely anchorage when text explains image, illustration when image explains text, and relay when text and image are equal, both contributing their meanings to a higher unit. A creative combination of the two inspirations resulted in a systematic classification of relations presented in Figure 1 below.

As the chart in Figure 1 shows, the taxonomy evolves around two basic principles: the status and the logicosemantic relationship. The text and image are equal in status when they are not dependent on each other; they can be but do not need to be part of a larger whole (they are either independent or complementary), whereas the unequal status means that one modifies the other and the modifying element is dependent on the modified one. The logico-semantic relations reflect the relations of expansion and projection. Expansion is realized either 
through exposition when both the text and the image are on the same level of generality, or through exemplification with either text or image more general. With extension, text or image adds related information, and in the case of enhancement, text or image provides circumstances to what is expressed in the counterpart. The relationship of projection is very rare within the corpus analysed; it relates either to the conveyance of wording or meaning in text and diagrams, or even more eloquently, texts in bubbles and relevant images in comic strips.

Rather than delving into more detail in the characteristics of the respective phenomena in the taxonomy, the study will proceed to the analysis of the corpus providing due specifications by means of concrete examples.

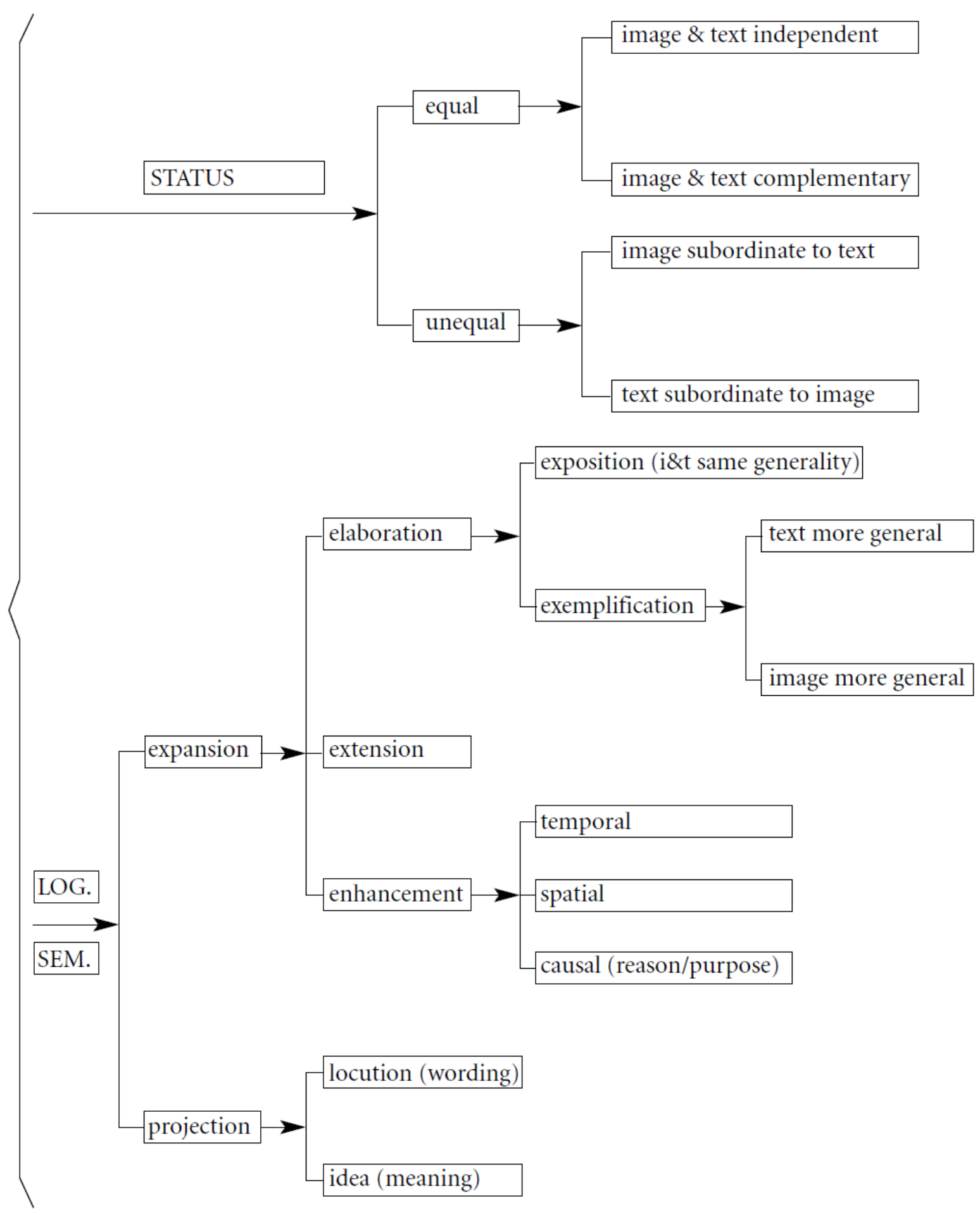

Figure 1: Text-image relations according to Martinec and Salway (2005) 


\begin{tabular}{|l|c|l|c|}
\hline \multicolumn{4}{|c|}{ Status of the text and the image } \\
\hline Number of images & 138 & Number of text-image relations $155 / 100 \%$ \\
\hline Equal status & $\mathbf{8 5 / 5 5 \%}$ & Unequal status & $\mathbf{7 0 / 4 5 \%}$ \\
\hline Independent status & $66 / 78 \%$ & Image sub. to text & $39 / 56 \%$ \\
\hline Complementary st. & $19 / 22 \%$ & Text sub. to image & $31 / 44 \%$ \\
\hline \multicolumn{3}{|c|}{ Independent $66 / 43 \%$} & Integrated (complementary + unequal) \\
\hline
\end{tabular}

\section{Table 1: The status of the text and the image}

The small-scale corpus consists of 28 blog posts which yields 138 images and a total of 18,660 words. The posts come from student blogs of five universities, namely Harvard, Cornell and Warwick universities, the University of Cambridge, and the University of Bournemouth. All posts selected are relatively recent, covering the last two years (2014-2016), accessed between January and August 2016.

\section{Research results and discussion} Applying Martinec and Salway's classification, the analysis of multimodal blog posts has resulted in a quantitative survey of the types of interaction between texts and images employed, and qualitative findings indicating an array of roles the images play in interplay with texts in the process of meaning-making, and possible correspondences between the nature of relations and the register of the verbal mode.

\subsection{Text-image relationships in numbers} The following tables show the degrees to which the texts and images explored are integrated and the ways in which they cooperate to convey the message intended. As indicated in Table 1 , the number of images (138) is lower than the number of relationships (155) they enter into with texts; this multiplicity reflects the fact that images tend to be accompanied by captions and at the same time can enter into a variety of relations with the text of the blog post as such. The nature of relations between images and captions, and between images and the mainstream text are often of a different nature (see 2.2).

Following Martinec and Salway's methodology, an important dividing line is drawn between text-image complexes in which the text and the image are not subordinated to one another but are positioned on the same level in the process of meaning-making: either each carrying its own message, or co-constructing one meaningful unit in a complementary way, and text-image ensembles in which the components are dependent on each other for interpretation. When considered from the point of view of the level of integration of the two modes into one whole, however, the dividing line could be shifted to distinguish the independent status from the rest, i.e. the loosely related texts and images with zero integration from pairs that are to a certain degree integrated into one another - the integrated pairs can thus include also texts and images of equal status which complement each other in the making of the message. Whereas the status defines more than half of text-image relations as equal, the number of complementary and unequal relations reveals that the amount of integrated complexes exceeds $50 \%$ of all relations examined. These results suggest that rather than only decorating the posts, images in blogs tend to co-create the message, forming a coherent whole with the texts.

The logico-semantic relations of the paradigm defined by Martinec and Salway are not represented proportionately: certain types of relations clearly dominate, particularly exemplification with the text providing a broader scope of information and the image visualizing selected elements, which makes the image dependent on the text for interpretation. A significant number of components are connected by extension, which means that either the text or the image extends the message conveyed, adding new details. The third most frequent type of relation is exposition, a looser connection in which the components do not manifest differences in the levels of generality/ specificity.

Table 2 below presents the shares of individual logico-semantic relations texts and images in blog posts are tied with. 


\begin{tabular}{|l|c|}
\hline \multicolumn{2}{|c|}{$\begin{array}{l}\text { Logico-semantic relations of texts and } \\
\text { images }\end{array}$} \\
\hline $\begin{array}{l}\text { Number of text-image relations } \\
155 / 100 \%\end{array}$ & $25 / 16.1 \%$ \\
\hline exposition & $69 / 44.5 \%$ \\
\hline $\begin{array}{l}\text { exemplification (text } \\
\text { more general) }\end{array}$ & $21 / 13.5 \%$ \\
\hline $\begin{array}{l}\text { exemplification (image } \\
\text { more general) }\end{array}$ & $31 / 20 \%$ \\
\hline extension & $7 / 4.5 \%$ \\
\hline enhancement & $1 / 0.6 \%$ \\
\hline projection - meaning & $1 / 0.6 \%$ \\
\hline projection - wording &
\end{tabular}

Table 2: Logico-semantic relations of texts and images

\subsection{Text-image relationships in single and double ties to text}

As shown in Table 1 and commented on in chapter 2.1, texts and images in blog posts enter either in simple or in multiple relations; ties can be multiplied in posts which exhibit two text-flows: the mainstream text of the post and a set of captions paired with photographs that alternate with the mainstream text. This possibility of multiplication is, however, not always utilized. Images can be interrelated solely with the caption texts. For example the text of caption "Above: Chocolate Peanut Butter Pie I made for this proctor for Proctor Appreciation Day!", attached to an image at

https://college.harvard.edu/admissions/h ear-our-students/student-blog/top-3-

study-breaks, and the image itself are not dependent on each other for interpretation - their status is independent; the caption at the same time provides additional information to the image, adding the information on who made the cake and for whom - the text is thus related to the image through the relation of extension. As the text of the post itself does not mention either the cake or Proctor Appreciation Day, there is no link to be found between the image and the mainstream text, the only bridge connecting this caption-image complex and the mainstream text consists in the anaphoric expression "this proctor" referring back to the preceding linguistic context and thus providing a tie between the two text flows.

The following image (Figure 2) on the other hand is interlocked with the text through a double tie: the image is linked both to the caption ("Narrowly avoiding death by passing Midland traffic whilst trying to photograph this cutie", see Figure 2 ) and to the text of the post preceding a set of photographs:

Spending the remainder of my week helping out at the departmental open days for prospective students, I also made another spontaneous trip into Warwick and Kenilworth just because, well... because I could.

http://studentblogs.warwick.ac.uk/hisp anic/entry/keep_calm_and/

In both relations the status of text and image is unequal. The text of the caption is subordinate to the image as its meaning cannot be interpreted without it: the expression "this cutie" is only understandable when paired with the cat seen in the window in the picture to which the caption provides an extension, adding information about the place and the street that the image itself does not offer. The image is though at the same time subordinate to the text of the post: it is only with the help of the text that the image can be identified as representing Warwick or Kenilworth, realizing the logico-semantic relation of exemplification: the picture shows just a selected feature of the towns mentioned in the text; the text is thus more general than the image.

The examples differ in the ways the image and the text are related and consequently in the degree to which they are integrated into one meaningful message; they evince, however, another distinctive feature that suggests the potential complexity of text-image relations in blogs: whereas in the Harvard example mentioned the relation is not only single (joining the image to the caption exclusively) but also bilateral, joining one image with one text component, in the example represented by Figure 2 only the caption relates to one image; the post text mentioning Warwick and Kenilworth relates to two image presenting half-timbered houses (see the printscreen in Figure 2, where the preceding picture could be recognized, too). As will be shown in the following chapter, ties could exhibit local or global reach, either building one-to-one relationships, or holding across chains of images and/or texts. 


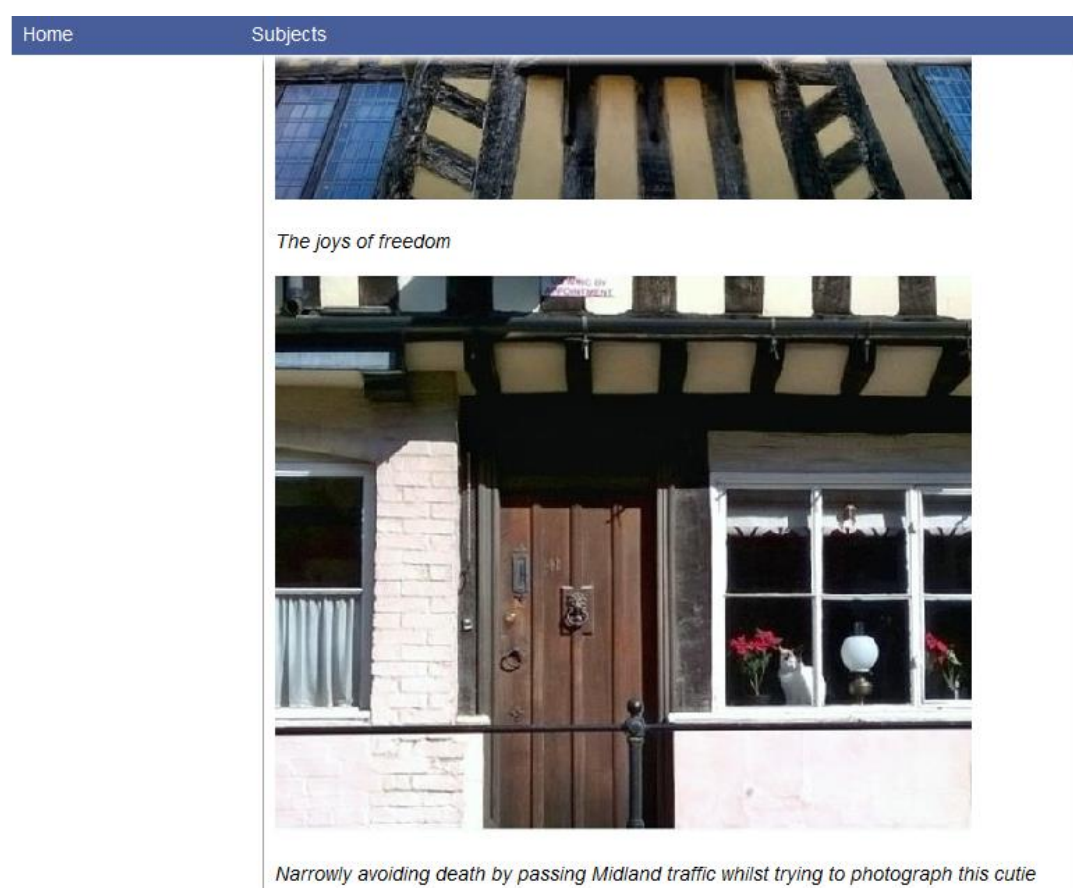

Figure 2: Image with a double tie to caption and text respectively http://studentblogs.warwick.ac.uk/hispanic/entry/keep_calm_and/

\subsection{Relations across text-image chains \\ 2.3.1 Constructing visual narratives}

As exemplified above, the reach of the constituents of text-image ties may exceed a one-to-one relation and run across the post to link a chain of images and texts. In the corpus analysed it is always the text that offers a link to more than one image and possibly also to relevant parts of the post text. The textual link with such a global reach can either precede or follow the chain it builds and is typically realized as a general noun (Halliday and Hasan, [1976] 2013, pp.274-276), or even more precisely as a shell noun as defined by Schmid (1998, 2000). Whereas general nouns are characterized within Halliday and Hasan's classification of cohesive devices as a category of hyponymy, as a set of nouns whose general meaning tops off the hierarchy of superordinacy (e.g. thing, problem, or issue), Schmid's concept is shaped by a cognitive view of the function of shell nouns recognizing that rather than by inherent semantic properties they may be defined by the role they play in discourse; in his view the shelling function arises in a specific context and can thus be attributed to a great variety of nouns and not all of them are necessarily semantically vague. The following examples suggest that the complex information shell nouns typically encompass need not be represented in the verbal mode only.
The extract below (Figure 3) shows a part of a blog post in which the author reminisces about her last year at the university, introducing a series of flashback texts and photographs with an opening sentence "I've made many unforgettable memories". The noun "memories" carries cataphoric reference and shells the subsequent chain of six images and related comments, which are either of an equal status with the text extending the message of the picture (see Figure 3 ) or of an unequal status with the text defining the event and the image exemplifying it.

The "shelling process" can be also anaphoric, the shell expression referring backwards to a row of pictures and texts as illustrated by the final paragraph of a post exemplified below. The phrase "the play by play of my weekend" rounds off the narrative of both the text and images through anaphoric reference:

Well there you have it! I hope you liked the play by play of my weekend complete with photos. This was my last weekend in Chile, so I went out with a definite bang. Next time I post, it will be from the United States! Crazy how time has flown while I've been here. ¡Adios! http://ro.drclas.harvard.edu/blog/week end-atacama 


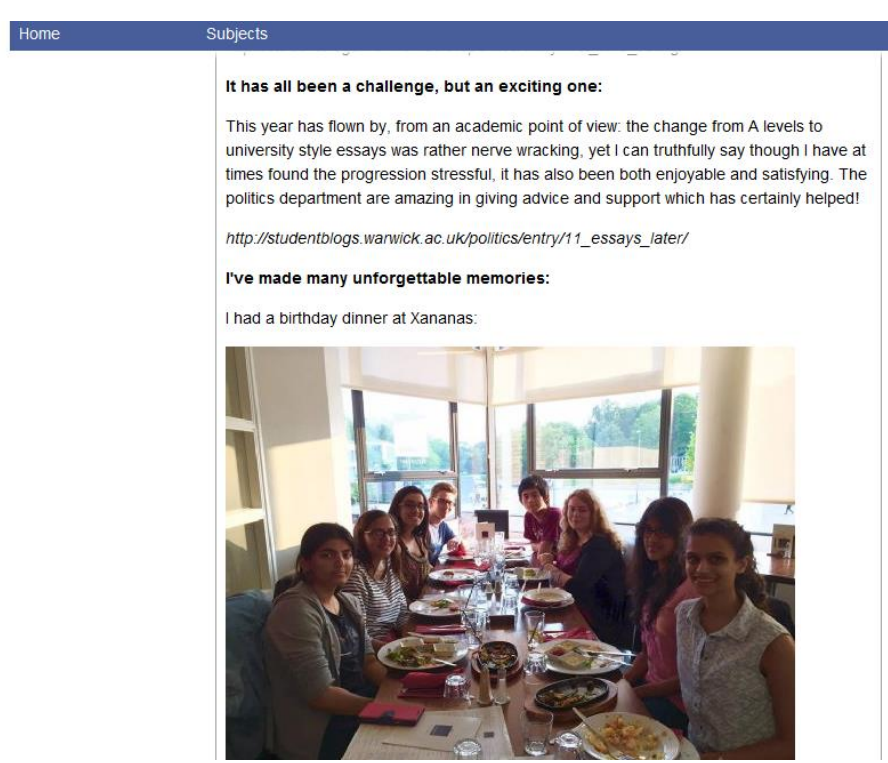

Figure 3: Introducing the text-image story - cataphoric reference http://studentblogs.warwick.ac.uk/politics/entry/first_year_reminiscing/

Whereas the series of images and comments presenting the reminiscences illustrated in Figure 3 form a loosely related chain with a colony (cf. Hoey, 1986; 2001) or satellite structure (cf. ledema, 1994), the following examples of multimodal narratives exhibit closer, multilevel interconnections building (chronologically) organized sequences. Colony or satellite structures consist of relatively independent components that refer to and depend on for interpretation here only on the shell expression, not on each other. This means that the series does not need to be perceived as a whole and in a certain order, and even skipping some of the components does not challenge the coherence of the whole. The ties between texts and images in Figure 4 are on the other hand multiplied: the text preceding both photographs introduces them generally as "Lakeside" but at the same time the initial conjunction in the second caption ("And this is the view from outside my window") defines the text as a follow-up of the preceding caption related to the previous picture, and thus constructs an ordered set completed with a farewell rounding up the post ("Thanks for stopping by!")

Both captions also function as intersemiotic transition moves redirecting explicitly the attention of the reader/viewer from the text to the photograph, shifting the discourse from linguistic description to visual image (cf. O'Halloran, 2007, p.453). The status of the captions and images is unequal with the captions dependent on the pictures for interpretation in the way inexplicit structures in authentic conversation depend on the situational context. The exophoric reference in the captions combined with the farewell phrase thanking the reader/viewer for a visit imitates spoken interaction and evokes an impression of a personal encounter with the photographs providing the essential extralinguistic context.

As can be exemplified by another Harvard blog example at http://ro.drclas.harvard.edu/blog/weeken d-atacama, the multimodal sequences can also arise from cross-references between a caption and the preceding picture: whereas the text following the photograph of a group of students covered by steam from geysers relates solely to this image and is dependent on it for its interpretation ("Please keep in mind that this photo was taken at 7 a.m. ..."), the second photograph of the same group in swimsuits is commented on by a text which at the same refers to the previous picture ("Believe it or not, the swift change in wardrobe only happened about 500 meters away from where the previous picture was taken."); in other words this text is only understandable when associated with both photographs presented. With the branching interrelations between texts and images the language of the post becomes even more conversationalized, and similarly to authentic spoken interaction, its interpretation becomes crucially dependent on the extralinguistic context provided here by the pictures. Even though both blogs, illustrated in Figure 4 and the 


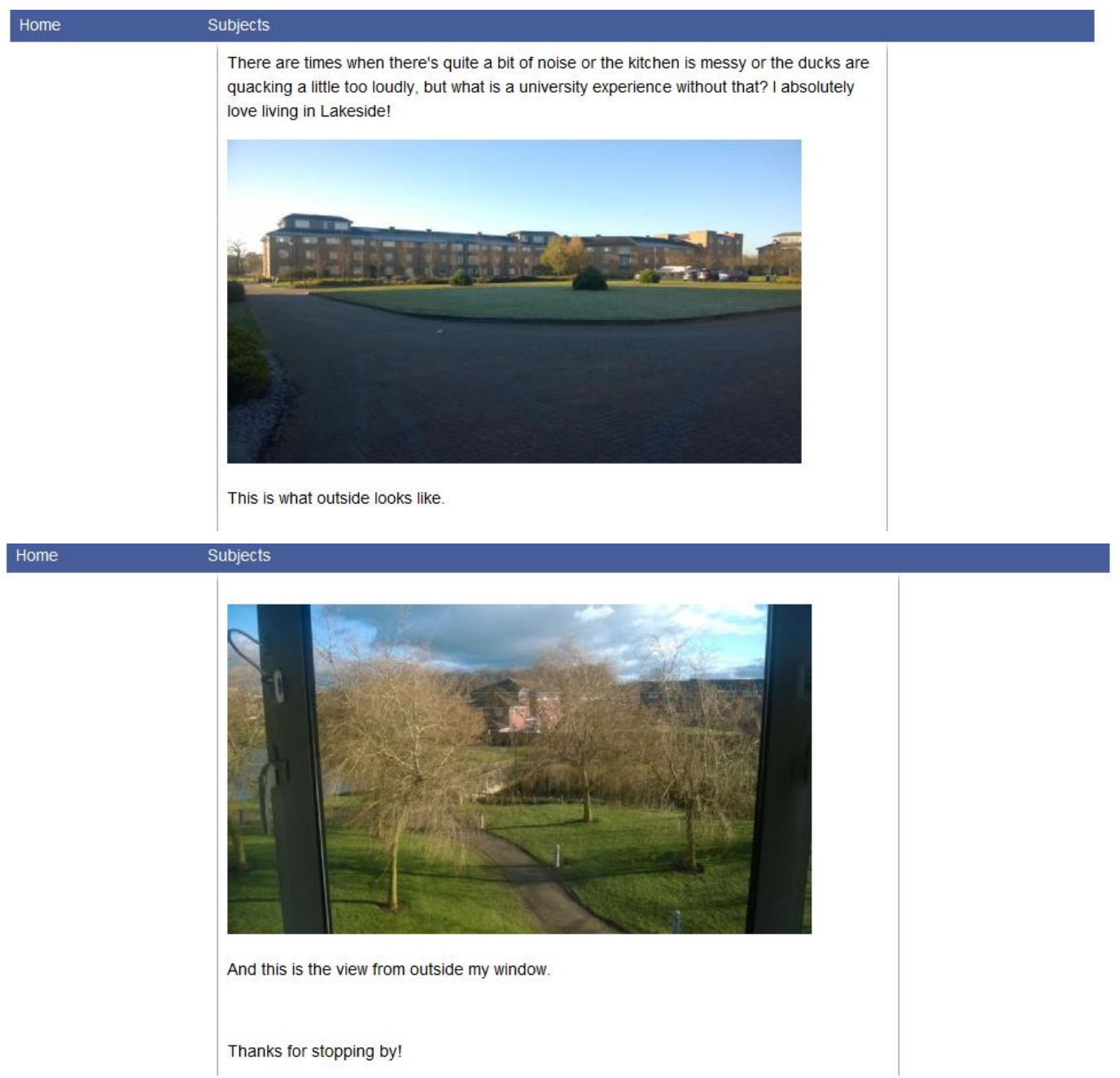

Figure 4: Multimodal sequence with inter-caption ties

http://studentblogs.warwick.ac.uk/economicspg3/entry/living_in_lakeside/

Harvard blog respectively, use photographs to construct the situational context for the post, the nature of the contextualization is not identical. Whereas in the Warwick blog (Figure 4) the text-image interplay suggests the physical presence of both the producer and the receiver at the location, in the Harvard blog referred to above the text refers to images overtly as to photos and the text-image interplay creates the atmosphere of a chat over holiday photographs.

Photographs in student blog posts typically offer an insight into the bloggers' personal lives through their authentic, private photo albums and thus co-construct the individualized view of student life the student blog as a genre represents. The pair of photographs at

https://college.harvard.edu/admissions/h ear-our-students/student-blog/cutthroator-not-common-questions-about-academic-

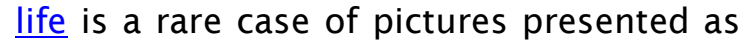

not only taken but also staged for the purpose of the blog post. The post titled "Cutthroat or not? Common Questions about Academic Life at Harvard" aims to undermine the stereotypical perception of Harvard student life as charged with a competitive and unfriendly atmosphere. In the first picture of the post the students perform the non-existent fear and animosity; the second picture, although staged as well, is accompanied with a caption introducing it as "candid", and enacts the actual atmosphere of joyful collegiality. The contrast between the two text-image complexes is highlighted by the syntactic parallelism and lexical cohesive ties connecting the captions, and parallelism in the composition and content of the pictures: the features which are held constant help foreground the variable components and vice versa - the meaning of the post thus stems from the mutual interplay of the constants and variables in 
both the captions and the images (for more detail on constant-variable interplay see Tárnyiková, 2008; Tomášková, 2012).

\subsubsection{Layout and the process of meaning- making}

As illustrated in the preceding chapter, texts and images within the posts enter into a variety of relations differing in their quality, namely in the status of the participating components and their logicosemantic relationship, and in the density of interconnections and cross-references. Whereas equal status and mutual independence of texts and images tend to correspond with the colony nature of the post structure, unequal status and mutual dependence of texts and images defies the discontinuity of colony organization, and, on the contrary, requires continuous structuring and linear reading/viewing of the post. In colonies the meaning arises from the affiliation of the colony components to the global topic of the text, or the multimodal ensemble; in continuously structured posts, however, the interpretation derives from the interrelations between texts and images in the post, and relies also on their adjacency or the order of the sequence. The meanings of texts and images may depend on other texts and images in a variety of ways, and their mutual contextualization is facilitated by, or virtually grounded in, the layout of the post. The layout can contribute to the development of an interplay of texts and images into a visual narrative. The present student blog analysis thus validates Bateman's approach (2014, pp.197-198) stressing the indispensable share the layout has on the coherence of a multimodal ensemble and meaningmaking, and challenging Martinec and Salway's view that "Layout certainly plays a role, particularly in machine-recognizable realizations, but the more important realizations involve elements of structure of text and images themselves" (338).

The layout, however, can be essential for recognizing the corresponding elements in interacting images and texts: the layout is crucial e.g. in the interpretation of the relation between the general meaning of an expression and its particular, culturespecific realization in the adjacent image (see for example the image of a hostel in a Harvard blog post at http://ro.drclas.harvard.edu/blog/weeken d-atacama). As explained by Jakobson $(1971, p .707)$ "The properly generic meanings of verbal signs become particularized and individualized under the pressure of changeable contexts or of nonverbalized but verbalizable situations", and in multimodal genres this individualizing context is co-built by texts and adjacent images - it is the adjacency of the text and the image that helps identify the building in the picture as a hostel. Layout organization is equally important when an element of the image pertains to a metaphorical expression in the text. In Figure 5 it is again the adjacency of the picture and the text that leads the reader/viewer to associating the lakeside pals with the ducks in the photograph. The proper interpretation of the interplay of texts and images is regularly facilitated by their adjacency within the layout of the blog post.

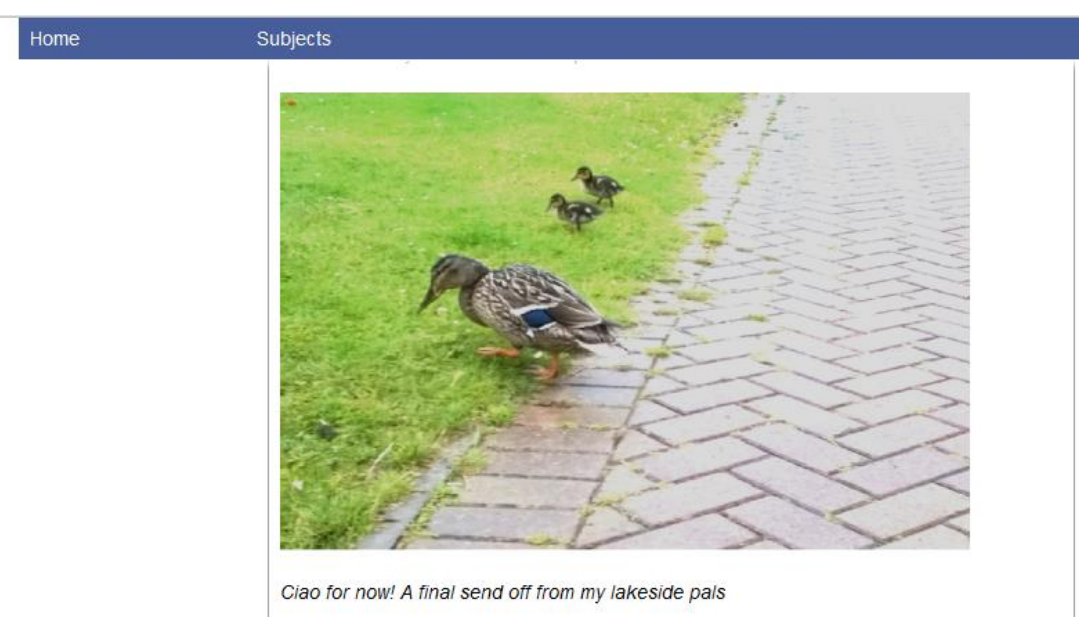

Figure 5: Interpretation of metaphorical expressions

http://studentblogs.warwick.ac.uk/hispanic/entry/keep_calm_and/ 


\section{Conclusion}

Student blogs as parts of institutional university websites help to "deinstitutionalize" institutional discourse, balancing the formality, impersonality and largely monologic character of institutional administration with informal, personalized and conversationalized discourse open to interaction. The affordances of the digital medium facilitate the personalized use of authentic photographs, whose interplay with the texts of the posts offer a highly individualized view of the university experience.

The texts and images within student blogs that were explored enter into an array of relations which tend to have a scalar character. In general their ties are either very loose, or quite tight with variation in between these two extremes. Even loosely related texts and images construct a coherent message as they meaningfully contribute to the global topic of the post but are not dependent on each other for interpretation and their interpretation is thus not dependent on their position within the layout. In this case the text-image complex of the blog post complies with the defining features of a discourse colony. Closely tied texts and images are dependent on each other for interpretation, interact through deictic expressions and intersemiotic transition moves and require adjacent and possibly also ordered position in the text-image sequence in the post.

Text-image relations often grow into dense and complex networks interconnecting one or two text-flows, namely the mainstream text of the post and the set of captions commenting on the images, and sets of images, including cross-references running across the post and developing text-image complexes into visual narratives.

The analysis confirms Bateman's conclusion of an overview of research into text-image interplay showing "that elements in a multimodal whole are mutually modifying, making it highly problematic to attend to language or any other mode in isolation" (2014, p.25). Higher integration of texts and images correlates with conversationalized language use: lexico-grammatical choices exhibit orality features imitating spoken interaction and a personal encounter referring to images as representing the situational context. Low or zero integration of texts and images tends to support written-like language which does not rely on the immediate situation for interpretation.

As explained in the introduction, the genre of blog is diversified and the diversity applies also in its multimodal realization: student blogs can appear as purely verbal; student blogs exploit the interplay between verbal and non-verbal modes - images can alternate with gifs or videos; student blogs, however, can also exclude the verbal mode completely, offering Instagram stories instead. With its transmedia potential, the blog as a genre suits the fluid nature of the internet environment well, and nested within university websites, freshens up the steady character of institutional discourse.

To reveal the full potential of the interplay of modes within student blogs, further research will need to reach beyond the investigation of static images of photographs to explore the role of gifs and videos and their mutual interaction. Although the student blog is only one of many genres on the web deriving its meaning from a complex text-image cooperation - there is e.g. an array of other sub-genres of the blog, video interviews, a diversified field of YouTube videos and Facebook time lines and chats - it is particularly interesting as a personalized, informal genre integrated into university websites, indicating the changing character of institutional discourse and the tendencies related to the development of this domain.

\section{Acknowledgment}

This article is an output of the internal grant project SCS20/FF/2016 (Genres and New Media) at the University of Ostrava.

Edited images from blog posts retrieved from Warwick University courtesy of their authors.

\section{References}

BARTHES, R., 1997a [1961]. The photographic message. In: R. Barthes, ed. Image-music-text. London: Fontana, pp. 15-31. 
BARTHES, R., 1997b [1964]. Rhetoric of the image. In R. Barthes, ed. Image-music-text. London: Fontana, pp. 32-51.

BATEMAN, J., 2011. The decomposability of semiotic modes. In: K. L. O'Halloran and B. A. Smith, eds. Multimodal studies. Exploring issues and domains. London: Routledge, pp. 17-38. BATEMAN, J., 2014. Text and image: A critical introduction to the visual/verbal divide. London: Routledge.

BATEMAN, J. and WILDFEUER, J., 2014. A multimodal discourse theory of visual narrative. Journal of Pragmatics, vol. 74, pp. 180-208.

BAZERMAN, C. and PRIOR, P., eds. 2004. What writing does and how it does it: An introduction to analyzing texts and textual practices. London: Lawrence Erlbaum Associates, Publishers.

HALLIDAY, M. A. K. and HASAN, R., 2013 [1976] Cohesion in English. London: Routledge.

HALLIDAY, M. A. K. 1978. Language as social semiotic. London: Edward Arnold.

HALLIDAY, M. A. K. and MATTHIESSEN, C. M. I. M. 2004. An introduction to functional grammar (3rd ed.). London: Hodder Education Publishers.

HERRING, S. C. et al. 2005. Weblogs as a bridging genre. Information Technology \& People, vol. 18, no. 2, pp. 142-171.

HOEY, M. 1986. The discourse colony: A preliminary study of a neglected discourse

type. In: M. Coulthard, ed. Talking about text. Studies presented to David Brazil on his retirement. Birmingham: Birmingham Instant Print Ltd., pp. 1-26.

HOEY, M. 2001. Textual interaction. An introduction to written discourse analysis. London and New York: Routledge.

IEDEMA, R. et al. 1994. Media literacy. Sydney: Disadvantaged Schools Programme, NSW Department of School Education.

JAKOBSON, R., 1971. Selected writings II. Word and language. The Hague: Mouton \& Co.

KRESS, G., 2009. What is mode? In: C. Jewitt, ed. The Routledge handbook of multimodal analysis. Abingdon: Routledge, pp. 54-68.

KRESS, G. 2010 . Multimodality. A social semiotic approach to contemporary communication. Abingdon: Routledge.

KRESS, G. and VAN LEEUWEN, T., 2006 [1996]. Reading images. The grammar of visual design. Abingdon: Routledge.

LEMKE, J., 2012. Multimedia and discourse analysis. In: P. J. Gee and M. Handford, eds. The Routledge handbook of discourse analysis. London: Routledge, pp. 79-89.

MARTINEC, R. and SALWAY, A. 2005. A system for image-text relations in new (and old) media. Visual Communication, vol. 4, no. 3, pp. 337-371. [Accessed 20 April 2016]. Available at: http://vcj.sagepub.com/content/4/3/337

O'HALLORAN, K. L., ed. 2004. Multimodal discourse analysis. London and New York: Continuum.

O'HALLORAN, K. L., 2008. Systemic functional-multimodal discourse analysis (SF-MDA): Constructing ideational meaning using language and visual imagery. Visual Communication, vol. 7, no. 4, pp. 443-475.

O'HALLORAN, K. L., 2012. Halliday and multimodal semiotics. SemiotiX new series: A global information bulletin. Semiotix XN-7 2012). [Accessed 15 August 2016]. Available at: http://www.semioticon.com/semiotix/2012/03/halliday-and-multimodal-semiotics/

SCHMID, H. J. 1998. Constant and ephemeral hypostatization: thing, problem and other shell nouns. In: B. Caron, ed. Proceedings of the 16th International Congress of Linguists (Paris, July 22-25, 1997), CD-ROM. Amsterdam: Elsevier. [Accessed 10 February 2017]. Available at: http://www.anglistik.uni-

muenchen.de/personen/professoren/schmid/schmid_publ/hypostatization.pdf

SCHMID, H. J. 2000. English abstract nouns as conceptual shells. From corpus to cognition, Berlin - New York: Mouton de Gruyter.

TÁRNYIKOVÁ, J. 2008. Role strukturních stereotypů v textu. In: C. Hopkinson, R. Tomášková and S. Wilamová, eds. Autorský záměr a jeho cesta $k$ adresátovi. Komunikační a textové strategie v masmediálním, komerčním a akademickém diskursu. Ends and means in language: Communication and textual strategies in mass media, commercial and academic discourse. Ostrava: Filozofická fakulta Ostravské univerzity v Ostravě, pp. 64-67.

TOMÁŠKOVÁ, R. 2012. Structural and cognitive stereotyping in lifestyle magazines for women. In: O. Dontcheva-Navratilova and R. Povolná, eds. Discourse interpretation: Approaches and applications. Newcastle upon Tyne: Cambridge Scholars Publishing, pp. 209-222. 
TOMÁŠKOVÁ, R. 2015. A walk through the multimodal landscape of university websites. Brno Studies in English, vol. 41, no. 1, pp. 77-100.

TOMÁŠKOVÁ, R. 2016. The polyphony of a super-genre: Blogs as a source of heteroglossia in university websites. In: R. Tomášková, Ch. Hopkinson and G. Zapletalová, eds. Professional genres from an interpersonal perspective. Newcastle upon Tyne: Cambridge Scholars Publishing, pp. 198-225.

Author's address and contact details:

Mgr. Renáta Tomášková, Dr.

Department of English and American Studies

University of Ostrava

Reální 5

Ostrava 1

Czech Republic

E-mail: Renata.Tomaskova@osu.cz 